\title{
A study on the Abruzzo 6 April 2009 earthquake by applying the RST approach to 15 years of AVHRR TIR observations
}

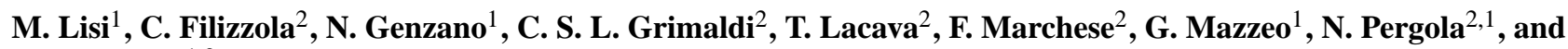 \\ V. Tramutoli ${ }^{1,2}$ \\ ${ }^{1}$ University of Basilicata, Department of Engineering and Physics of the Environment, Potenza, Italy \\ ${ }^{2}$ National Research Council, Institute of Methodologies for Environmental Analysis (IMAA), Tito Scalo (PZ), Italy
}

Received: 1 November 2009 - Accepted: 1 February 2010 - Published: 26 February 2010

\begin{abstract}
A self adaptive approach (RST, Robust Satellite Technique) has been proposed as a suitable tool for satellite TIR surveys in seismically active regions devoted to detect and monitor thermal anomalies possibly related to earthquake occurrence. In this work, RST approach has been applied to 15 years of AVHRR (Advanced Very High Resolution Radiometer) thermal infrared observations in order to study the 6 April 2009 Abruzzo earthquake. Preliminary results show clear differences in TIR anomalies occurrence during the periods used for validation (15 March15 April 2009) and the one (15 March-15 April 2008) without earthquakes with $M_{\mathrm{L}} \geq 4.5$, used for confutation purposes. Quite clear TIR anomalies appears also to mark main tectonic lineaments during the preparatory phases of others, low magnitude $\left(3.9<M_{\mathrm{L}}<4.6\right)$ earthquakes, occurred in the area in the same period.
\end{abstract}

\section{Introduction}

In the past years several studies (see for example Gorny et al., 1988; Qiang and Dian, 1992; Tronin, 1996; Qiang et al., 1997; Tronin et al., 2002; Ouzounov and Freund, 2004) have already reported the appearance of space-time anomalies in TIR (Thermal Infra-Red) satellite imagery before (from weeks to days) severe earthquakes. Such anomalies, located near the place and the time of an earthquake, have been attributed to the increase of green-house gas (such as $\mathrm{CO}_{2}$, $\mathrm{CH}_{4}$ ) emission rates (e.g. Qiang et al., 1991; Tramutoli et al., 2001, 2009, and reference herein), to the modification of ground water regime (e.g. Hamza, 2001), to the increase of convective heat flux (Qiang et al., 1991; Tronin, 2000), to

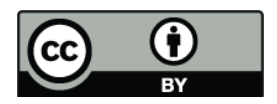

Correspondence to: $\mathrm{M}$. Lisi

(lisi@imaa.cnr.it) more complex phenomena (e.g. Pulinets et al. 2002, 2006, 2007; Ouzounov and Freund, 2004) all including, among the others pre-seismic effects, the increasing of near surface temperature.

Several studies have been published claiming the correlation among TIR signal fluctuations and earthquake preparation which were mainly affected by the absence of convincing testing steps (based, for instance, on a validation/confutation approach) and/or lacking for whatever attention to the possibility that other causes (e.g. meteorological), different from seismic activity, could be responsible for the observed TIR variations.

Moving also from these evident limits, a different approach, named Robust Satellite Technique (RST; Tramutoli, 2005, 2007) - formerly RAT (Robust AVHRR Technique, Tramutoli, 1998) - was proposed in order to investigate possible relations between earthquake occurrence and spacetime fluctuations of Earth's emitted TIR radiation observed from satellite.

In fact RST approach is based on a statistical definition of "TIR anomalies" and on a suitable method for their identification even in very different local (e.g. related to atmosphere and/or surface) and observational (e.g. related to the time/season or satellite view angles) conditions. Since its first implementation, it has been always carried out by using a validation/confutation approach, in order to verify the presence/absence of anomalous space-time TIR transients in the presence/absence of seismic activity.

Several earthquakes occurred in different continents (Europe, Asia, America and Africa), in various geo-tectonic settings (compressive, extensional and transcurrent) and with a wide range of magnitudes (from 4.0 to 7.9 ) have been analyzed by applying RST approach to different satellite TIR sensors (e.g. Tramutoli et al., 2001b, 2005, 2009; Di Bello et al., 2004; Filizzola at al., 2004; Corrado et al., 2005; Genzano et al., 2007, 2009; Aliano et al., 2007, 2008a, b, c).

Published by Copernicus Publications on behalf of the European Geosciences Union. 
In this paper the Abruzzo earthquake (6 April 2009, $\left.M_{\mathrm{L}} \sim 5.8\right)$ has been studied by applying the RST approach to 15 years of data acquired (in the TIR spectral band 10.3$11.3 \mu \mathrm{m}$ ) by AVHRR sensor flying onboard NOAA (National and Oceanic Atmospheric Administration) satellites. As usual the results obtained by RST analysis at the time of this earthquake (validation) will be compared with the ones obtained by an identical analysis performed over the same area, in similar observational conditions (same period) but in a seismically unperturbed (i.e. without earthquakes of similar magnitude) period (confutation).

\section{A robust estimator of thermal anomalies}

The RST approach is a general change detection method for satellite data analysis already successfully applied to monitor major natural and environmental hazards related to: flood risk (Tramutoli et al., 2001a; Lacava et al., 2005, 2006, 2010); volcanic activity (Pergola et al., 2001, 2004a, b; Tramutoli et al., 2001c; Di Bello et al., 2004; Bonfiglio et al., 2005; Marchese et al., 2006; Filizzola et al., 2007); forest fires (Cuomo et al., 2001; Mazzeo et al., 2007), etc. After its first application to the 1980 Irpinia-Basilicata's earthquake (Di Bello et al., 2004; Tramutoli et al., 2001b) RST has been applied to seismically active area monitoring for several other earthquake events: Athens, 7 September 1999 (Filizzola et al., 2004); Izmit, 17 August 1999 (Tramutoli et al., 2005); Gujarat, 26 January 2001 (Genzano et al., 2007), Boumerdes/Thenia, 21 May 2003 (Aliano et al., 2007); Hector Mine, 16 October 1999 (Aliano et al., 2008a), UmbriaMarche, October 1997 (Aliano et al., 2008b), Mestia Tianeti (Georgia) 23 October 1992 (Genzano et al., 2009) and various seismic events occurred in Greece and Turkey, in May and June 1995-1996 (Corrado et al., 2005).

RST is based on a preliminary multi-temporal analysis of several years (from 4 to 10 and more depending on the availability of historical data-sets) of homogeneous satellite TIR records co-located in the space-time domain, devoted to characterize the TIR signal (in terms of its expected value and natural variability range) for each pixel of the satellite image to be processed. On this basis, anomalous TIR patterns are identified as a deviation from those "normal" conditions, using a specific index, RETIRA (Robust Estimator of TIR Anomalies, Filizzola et al., 2004; Tramutoli, 2005), computed on the image at hand as in Eq. (1):

$$
\otimes_{\Delta T}(\boldsymbol{r}, t)=\frac{\Delta T(\boldsymbol{r}, t)-\mu_{\Delta T}(\boldsymbol{r})}{\sigma_{\Delta T}(\boldsymbol{r})}
$$

where:

$\boldsymbol{r} \equiv(x, y)$ represents location coordinates centre of the considered pixel on satellite image at hand;

$t$ is the time of image acquisition with $t \in \tau$, where $\tau$ defines the homogeneous domain of satellite imagery collected in the same time-slot of the day and period (month) of the year;

$\Delta T(\boldsymbol{r}, t)=T(\boldsymbol{r}, t)-T(t)$ is the value of the difference between the punctual value of brightness temperature $T(\boldsymbol{r}, t)$ at the location $\boldsymbol{r} \equiv(x, y)$ and acquisition time $t$, and its spatial average $T(t)$ computed on the investigated area considering only cloud-free locations, all belonging to the same, land or sea, class (i.e. considering only sea pixels if $\boldsymbol{r}$ is located on the sea and only land pixels if it is located on the land). Note that the choice of such a differential variable $\Delta T(\boldsymbol{r}, t)$ instead of $T(\boldsymbol{r}, t)$ is expected to reduce possible contributions (e.g. occasional warming) due to day-to-day and/or year-toyear climatological changes and/or season time-drifts;

$\mu_{\Delta T}(\boldsymbol{r})$ time average value of $\Delta T(\boldsymbol{r}, t)$ at the location $\boldsymbol{r} \equiv(x, y)$ computed on cloud free records belonging the selected data set $(t \in \tau)$;

$\sigma_{\Delta T}(\boldsymbol{r})$ standard deviation of $\Delta T(\boldsymbol{r}, t)$ at the location $\boldsymbol{r} \equiv(x, y)$ computed on cloud free records belonging the selected data set $(t \in \tau)$.

By this way $\otimes_{\Delta T}(\boldsymbol{r}, t)$ gives the local excess of the current $\Delta T(\boldsymbol{r}, t)$ signal compared with its historical mean value and weighted by its historical variability at the considered location. Both, $\mu_{\Delta T}(\boldsymbol{r})$ and $\sigma_{\Delta T}(\boldsymbol{r})$, are computed, once and for all, for each location $\boldsymbol{r}$, processing several years of historical satellite records acquired in similar observational conditions. They are two reference images describing the normal behaviour of the signal and of its variability at each location $\boldsymbol{r}$ in observational conditions as similar as possible to the ones of the image at hand. The difference $\Delta T(\boldsymbol{r}, t)-\mu_{\Delta T}(\boldsymbol{r})$ then represents the Signal (S) to be investigated for its possible relation with seismic activity. It is always evaluated by comparison with the corresponding natural/observational Noise $(\mathrm{N})$, represented by $\sigma_{\Delta T}(\boldsymbol{r})$ which describes the overall (local) variability of $\mathrm{S}$ including all (natural and observational, known and unknown) sources of its variability, as historically observed at the same site in similar observational conditions (sensor, time of day, month, etc.). In this way, the relative importance of the measured TIR signal (or the intensity of anomalous TIR transients) can naturally be evaluated in terms of $\mathrm{S} / \mathrm{N}$ ratio by the RETIRA index.

Being independent from a specific sensor/satellite system, RST can easily be exported on different satellite data, and applied to analyze different events in the world. However, a wider and more detailed description of the RST approach and its implementation on different satellite sensors to monitor seismic areas can be found in Tramutoli et al. (2005), Aliano et al. (2008a) and in others above mentioned papers.

\section{The case of Abruzzo earthquake}

The Abruzzo earthquake $\left(M_{\mathrm{L}} \sim 5.8\right)$ occurred on 6 April 2009 at 01:32:39 GMT, having its epicentre at $42.334 \mathrm{~N}$ and 13.334E (INGV, 2009) in central Italy. The main shock occurred as a result of normal faulting on a NW-SE oriented structure in the central Apennines. Since January 2009 the 


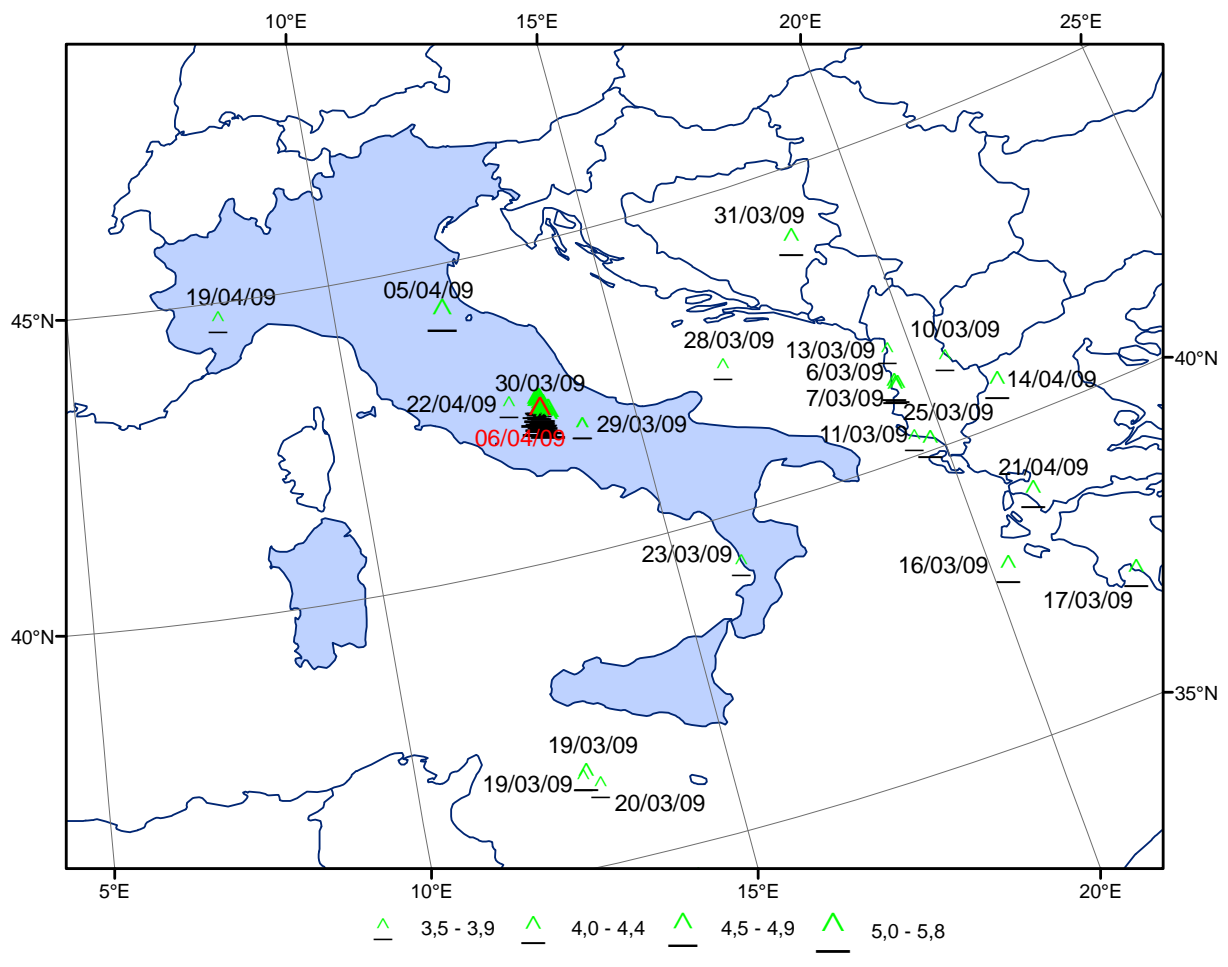

Fig. 1. Seismic events with $M_{\mathrm{L}}>3.5$ occurred in March and April 2009. Red star indicates the main shock of Abruzzo earthquakes (INGV, 2009).

zone has been object of frequent seismic events (Fig. 1) with characteristics of seismic swarm with hundreds of modest entity shake. The seismicity was confined in the upper crust and interested an area about $30 \mathrm{~km}$ long in the NW-SE strike direction, parallel to the Apennine mountain axis and to the main fault structures known in the area.

In order to perform the RST analysis on this event, 15 years (from 1995 to 2009) of NOAA-AVHRR data has been analyzed. The navigation of AVHRR data has been performed by SANA (Sub-pixel Automatic Navigation for AVHRR, Pergola and Tramutoli, 2000, 2003). Following RST prescriptions, in order to characterize TIR normal signal behaviour in the considered area and observation period (15 March-15 April), $\mu_{\Delta T}(\boldsymbol{r})$ and $\sigma_{\Delta T}(\boldsymbol{r})$ reference field (Fig. 2) were computed by using only AVHRR records collected:

- in the same time-slot (00:00-02:00 GMT),

- during the months of March and April,

- in cloud-free conditions.

The RETIRA index has been then computed for all the NOAA/AVHRR images in order to perform the following validation/confutation analyses. For validation purposes, the months of March and April 2009 have been considered, while, in the confutation phase, the analysis has been performed considering the months of March and April 2008: a seismically "unperturbed" year (i.e. no earthquakes with $M \geq 4.5$ in the same region and in the same months) in the considered data set.

\section{Validation}

On the basis of these reference fields, TIR anomaly maps have been computed for all AVHRR night-time $(00: 00 \div 02: 00 \mathrm{GMT})$ images in the period 15 March15 April 2009 (validation phase). Every scene has been processed but scenes affected by wide cloudy coverage ( $>80 \%$ of the total, like the one collected on 29 March 2009) as well as scenes clearly affected by a cold spatial average effect (Aliano et al., 2008a) due to the computation of RETIRA index on a very few number of cloud-free pixels have been excluded from further analyses (Fig. 3).

Figure 4 shows the results of the RETIRA index $\left(\otimes_{\Delta T}(\boldsymbol{r}, t)\right)$ computation since 15 March until to 15 April 2009. Pixels with $\otimes_{\Delta T}(\boldsymbol{r}, t) \geq 3$ (i.e. $\Delta T(\boldsymbol{r}, t)-\mu_{\Delta T}(\boldsymbol{r})$ excess greater than $\left.3 \sigma_{\Delta T}(\boldsymbol{r})\right)$ are depicted in red and hereafter, only for the sake of simplicity, we will refer to them as "TIR anomalies". Pixels affected by clouds have been identified by using OCA (One-channel Cloudy-radiance-detection Approach, Pietrapertosa et al., 2001; Cuomo et al., 2004), considered as missing data (as Earth's thermally emitted radiation is completely captured by meteorological clouds) and excluded from whatever following analysis. 


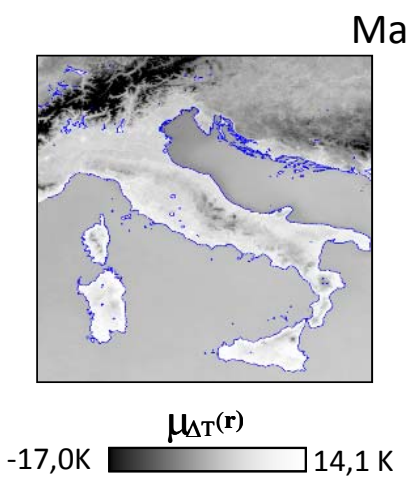

March

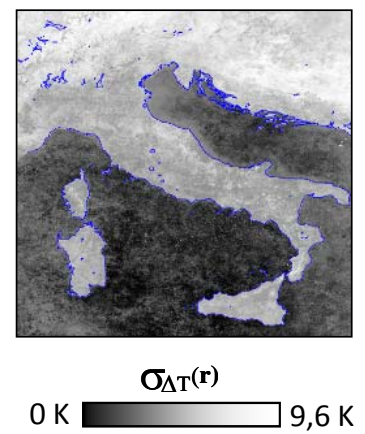

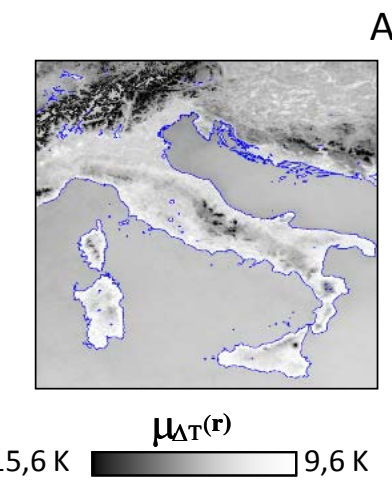

April

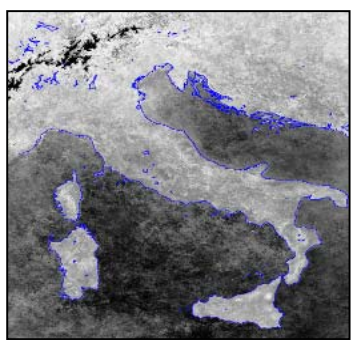

$0 \mathrm{~K} \stackrel{\sigma_{\Delta \mathrm{T}}(\mathbf{r})}{\longrightarrow} 9,5 \mathrm{~K}$

Fig. 2. Reference fields (time average $\mu_{\Delta T}(\boldsymbol{r})$ and standard deviation $\sigma_{\Delta T}(\boldsymbol{r})$ ) for the investigated area computed for March (left) and April (right) from AVHRR data acquired in the period 1995-2009 between 00:00 and 02:00 GMT.

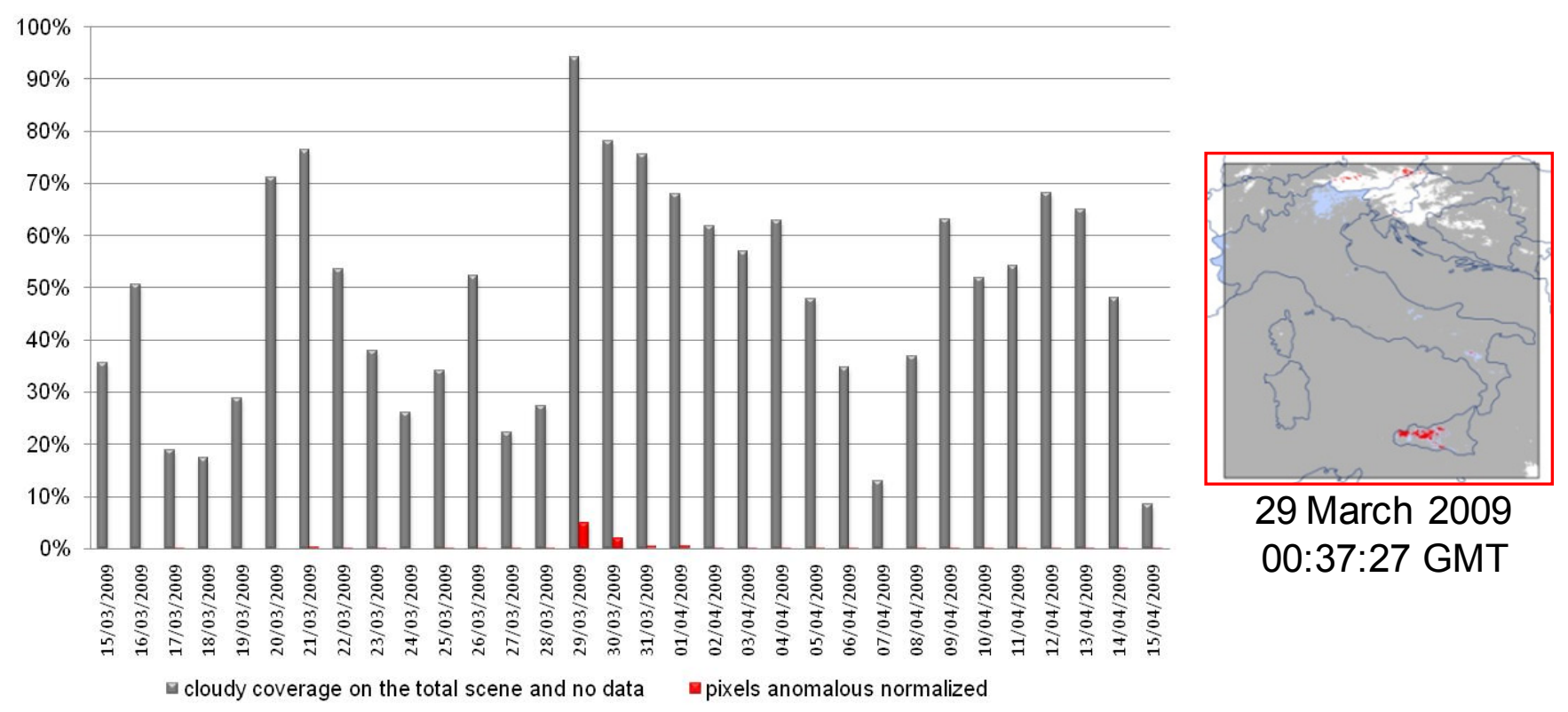

Fig. 3. Left side: calculation of cloudy coverage over all the AVHRR scenes processed for the 2009: grey bars represent the percentage of cloudy pixels over the total number of pixels in the image; red bars represent the percentage of TIR anomalies (RETIRA $\geq 3$ ) over the remaining cloud free pixels in the image. Right side: example, on 29 March 2009 scene, of artefacts (spurious TIR anomalies) due to the poorness of cloud-free pixels where RETIRA index can be computed and to the clouds masking quite all the warmest part of the scene (cold spatial average effect, see text).

Looking at the sequence of pictures in Fig. 4 it is possible to note that TIR anomalies (i.e. pixels with $\otimes_{\Delta T}(\boldsymbol{r}, t) \geq 3$ ) appear in the Italian peninsula affecting:

- the north of Italy on 31 March on Piedmont and Veneto region, on 3 April in Padania plain, on 13 April on Apuane Alps,

- the Central Italy on 30 March on East Coast, on 31 March and 10 April on Northern Apennines, on 1 April on Central Apennines,

- the south of Italy at 1 April on the West Coast.
TIR anomalies are present also in the Balkan area on Bosnia region on 31 March and 1, 4, and 6 April, while they affect the northeastern part of Croatia from 8 April until 13 April. Other anomalous pixels appear on 21 March on Mediterranean Sea, on 22 March on northern coast of Sardegna and on 14 April on eastern coast of Corsica.

In the following we will consider as significant only TIR anomalies that present the characteristics of spatial extension and persistence in time. In fact, as already discussed in previous works (Filizzola et al., 2004; Tramutoli et al., 2005; Aliano et al., 2008a), the RETIRA index is intrinsically not 


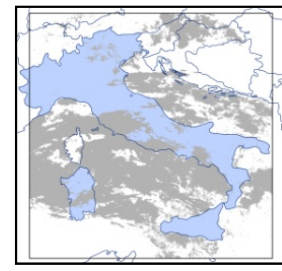

15 March 2009

01:24:17 GMT

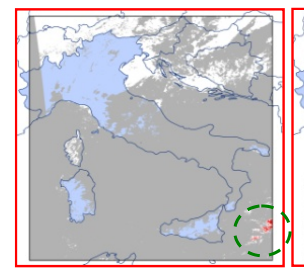

21 March 2009

00:20:58 GMT

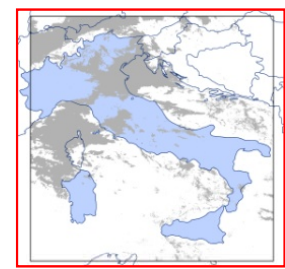

27 March 2009

00:58:36 GMT

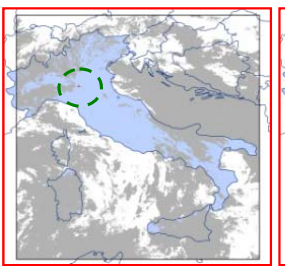

03 April 2009

01:25:37 GMT

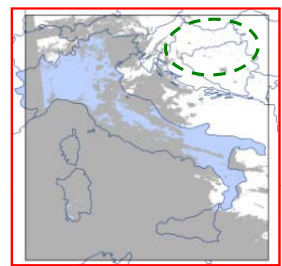

09 April 2009

01:13:47 GMT

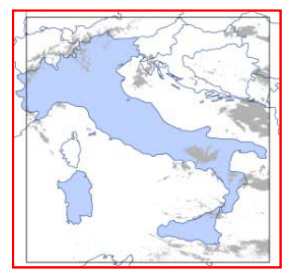

15 April 2009

01:53:11 GMT

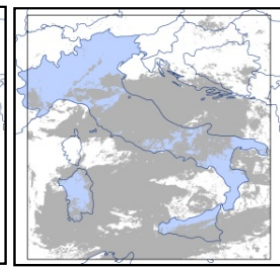

16 March 2009

01:13:44 GMT

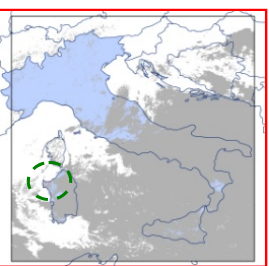

22 March 2009

01:46:30 GMT

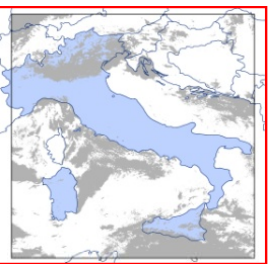

28 March 2009

00:43:50 GMT

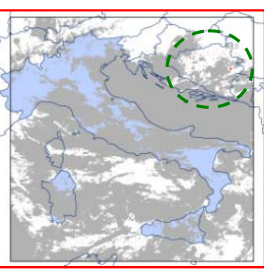

04 April 2009

01:15:03 GMT

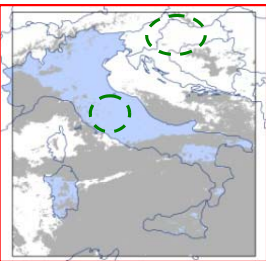

10 April 2009

01:52:49 GMT

$\square \otimes_{\Delta T}(\mathbf{r}, t) \geq 3$

clouds and no data

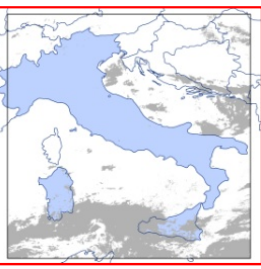

17 March 2009

01:03:11 GMT

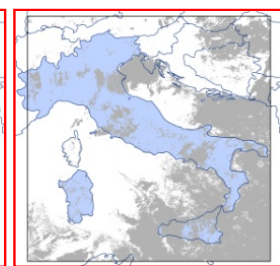

23 March 2009

01:35:59 GMT

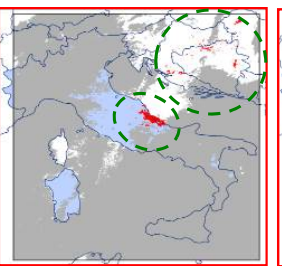

30 March 2009

00:22:57 GMT

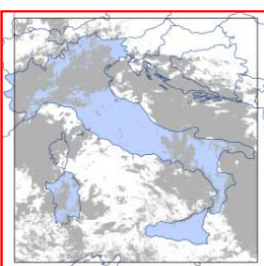

05 April 2009

01:04:33 GMT

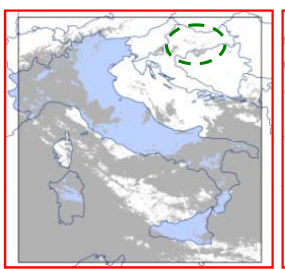

11 April 2009

00:53:13 GMT

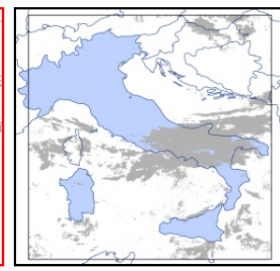

18 March 2009

00:52:35 GMT

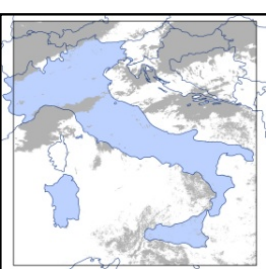

24 March 2009

01:30:15 GMT

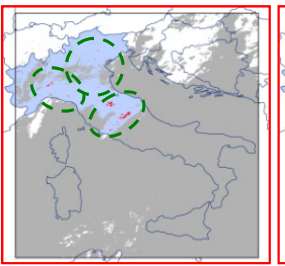

31 March 2009

01:57:31 GMT

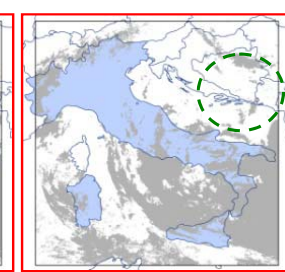

06 April 2009

00:53:56 GMT

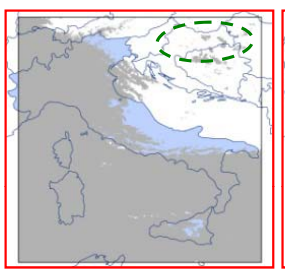

12 April 2009

01:31:13 GMT

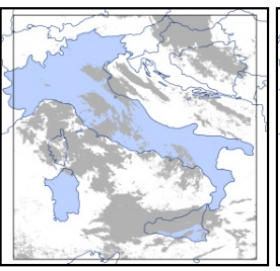

19 March 2009

00:42:09 GMT

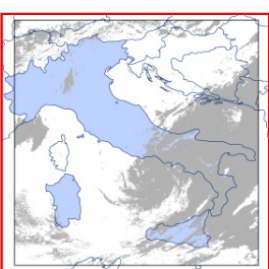

25 March 2009

01:19:39 GMT

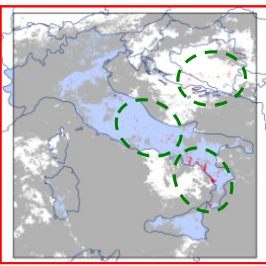

01 April 2009

01:46:49 GMT

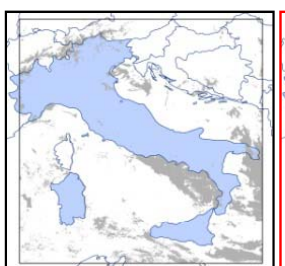

07 April 2009

00:43:25 GMT

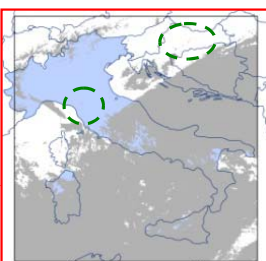

13 April 2009

01:20:57 GMT

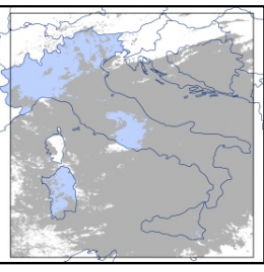

20 March 2009

00:31:30 GMT

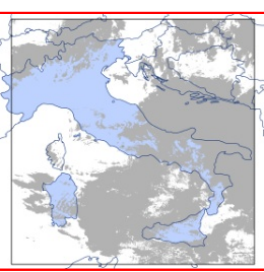

26 March 2009

01:09:12 GMT

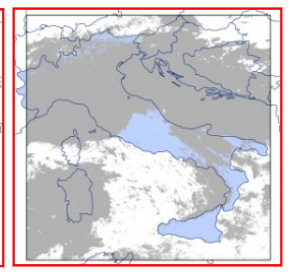

02 April 2009

01:36:14 GMT

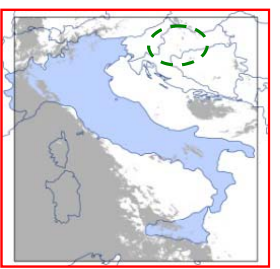

08 April 2009

00:32:49 GMT

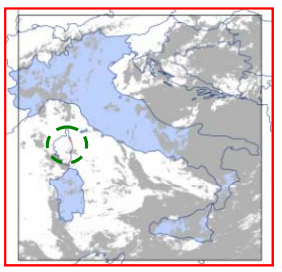

14 April 2009

01:10:28 GMT

Fig. 4. Validation: results of the RETIRA index computation on the investigated area before and after the Abruzzo earthquake (6 April 2009 , $\left.M_{\mathrm{L}} \sim 5.8\right)$. Pixels with $\otimes_{\Delta T}(\boldsymbol{r}, t) \geq 3$ are depicted in red. Cloudy locations are depicted in grey. Red boxes identify images containing at least 1 pixel with $\otimes_{\Delta T}(\boldsymbol{r}, t) \geq 3$. Green dashed ellipses indicate regions containing thermal anomalies discussed in the text. 

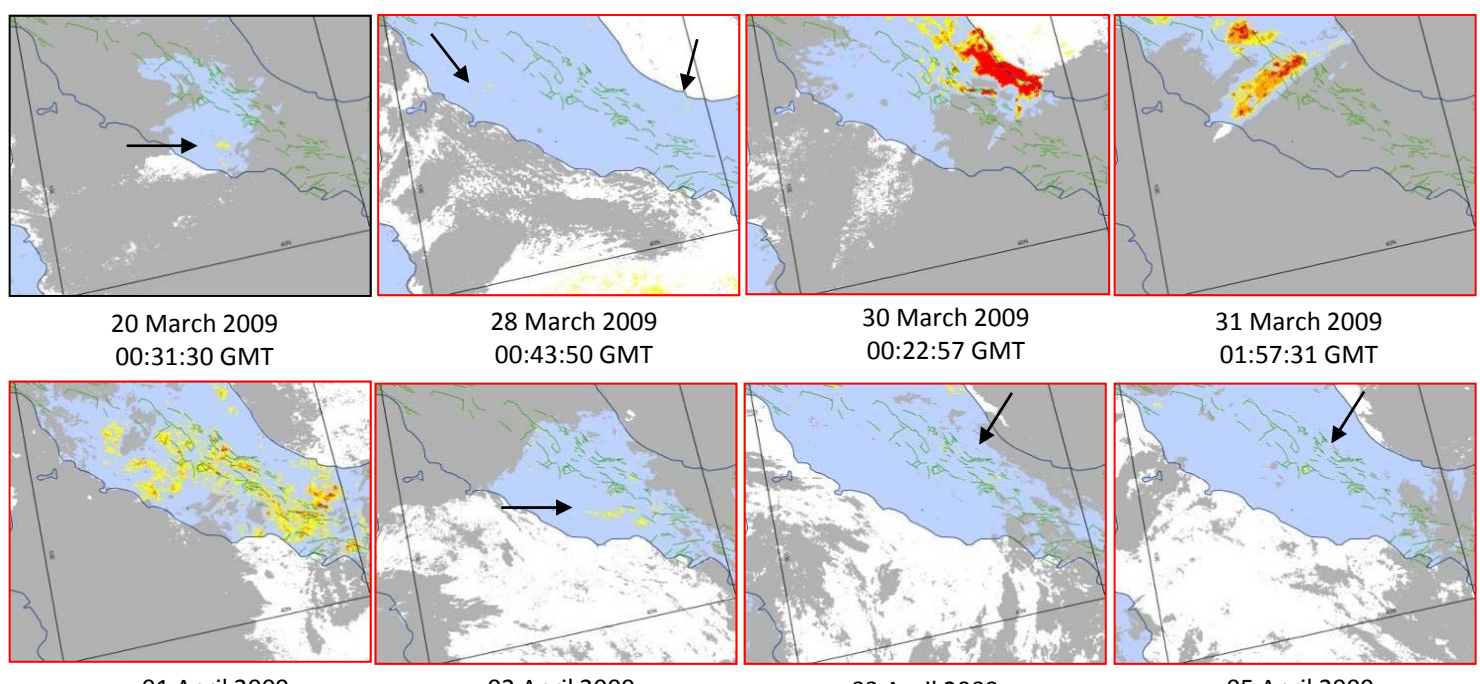

01 April 2009

02 April 2009

01:46:49 GMT

01:36:14 GMT

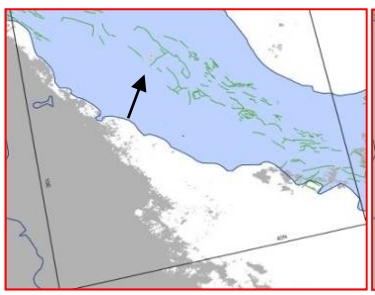

08 April 2009

00:32:49 GMT

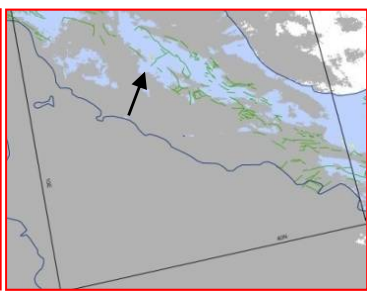

09 April 2009

01:13:47 GMT
03 April 2009

01:25:37 GMT
05 April 2009

01:04:33 GMT

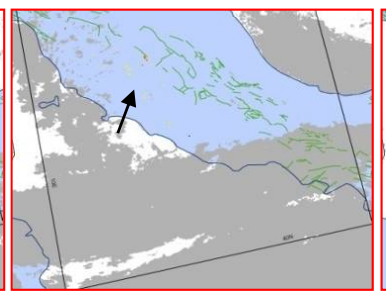

10 April 2009

01:52:49 GMT

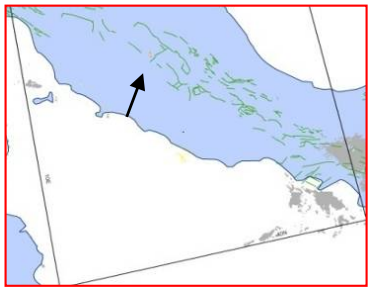

15 April 2009 01:53:11 GMT
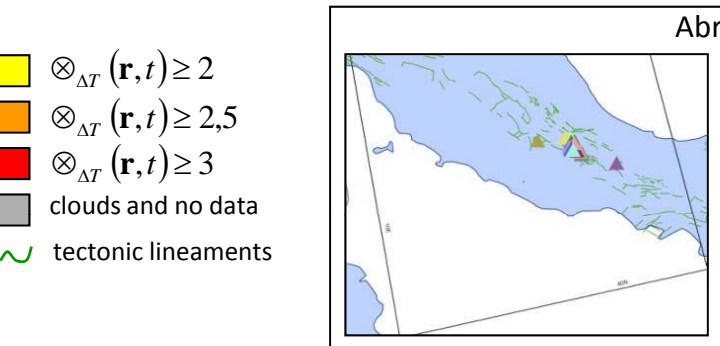

Abruzzo seismic events

A 06/04/2009 Ml 5.8 $\quad 08 / 04 / 2009$ Ml 4.3 $\quad 30 / 03 / 2009$ Ml 4

A $07 / 04 / 2009$ M| 5.3 A 06/04/2009 Ml 4.3 A 23/04/2009 Ml 4

A 09/04/2009 Ml 5.1 A 07/04/2009 Ml 4.2 A 09/04/2009 Ml 4

A $09 / 04 / 2009$ Ml 4.9 $\Delta$ 06/04/2009 Ml 4.2 A 29/03/2009 Ml 3.8

A $13 / 04 / 2009$ Ml 4.9 A 09/04/2009 Ml 4.2 A 22/04/2009 Ml 3.6

A $06 / 04 / 2009$ Ml 4.8 $A$ 06/04/2009 M| 4.2

A $06 / 04 / 2009 \mathrm{Ml} 4.7 \therefore 14 / 04 / 2009 \mathrm{Ml} 4.1$

A $07 / 04 / 2009 \mathrm{Ml} 4.7$ A $06 / 04 / 2009 \mathrm{Ml} 4$

- $06 / 04 / 2009 \mathrm{Ml} 4.6$ A $06 / 03 / 2009 \mathrm{Ml} 4$

Fig. 5. Validation: the sequence of Abruzzo (6 April 2009, $\left.M_{\mathrm{L}} \sim 5.8\right)$ earthquake. As in Fig. 4 but, in this case lower intensity $\left(\otimes_{\Delta T}(\boldsymbol{r}, t) \geq 2\right)$ TIR anomalies are also depicted in different yellow tones. The list of seismic events occurred during March and April 2009 is from INGV (2009).

protected from the abrupt occurrence of signal outliers related to particular natural (e.g. local warming due to nighttime cloud passages) or observational (e.g. errors in image navigation/co-location process) conditions. This is, for instance, the case of TIR anomalies detected along the northern coast of Sardegna at 22 March and along eastern coast of Corsica at the 14 April: the cause of this effect is very likely a navigation/co-location error (Fig. 4).

Moreover, false TIR anomalies can be produced when the computation of the spatial average term $T(t)$ (which contribute to determine the value of RETIRA index) is performed on a too small number of cloud-free pixels mostly concentrated in the colder portion of the scene (cold spatial average effect, Aliano et al., 2008a). This is evidently the case of TIR anomalies affecting the Mediterranean Sea on 21 March (Fig. 4). Excluding the above mentioned artifacts, very few sequences of spatially extended and time persistent TIR anomalies can be identified that are described with some detail in Figs. 5, 6, and 7.

In order to better analyze such sequences images in Figs. 5, 6, and 7 have been reconstructed also considering lower values of the RETIRA index (pixels characterized by $\left.\otimes_{\Delta T}(\boldsymbol{r}, t) \geq 2\right)$. In these figures it is easy to note that low intensity TIR anomalies generally follow the ones at higher relative intensities, noticeably enlarging the anomaly area and filling gaps both in the space (among isolated anomalous pixels) and time domains. 


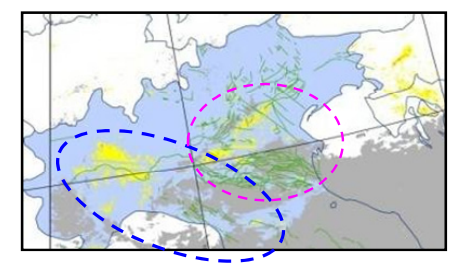

16 March 2009

01:13:44 GMT

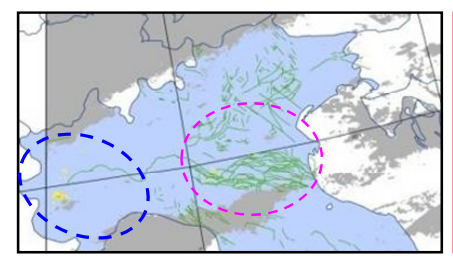

24 March 2009

01:30:15 GMT

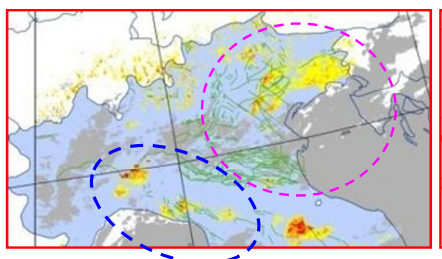

31 March 2009

01:57:31 GMT

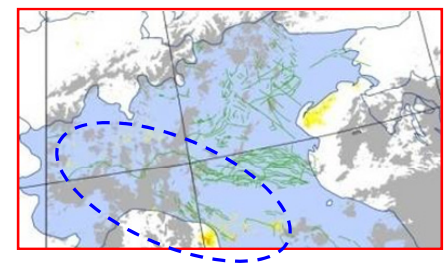

14 April 2009

01:10:28 GMT

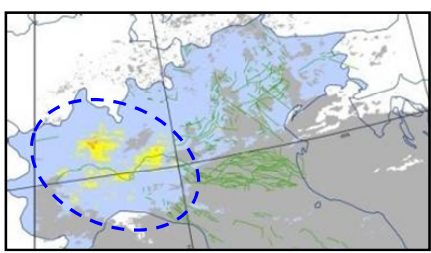

20 March 2009

00:31:30 GMT

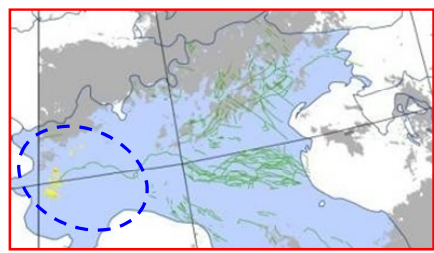

26 March 2009

01:09:12 GMT

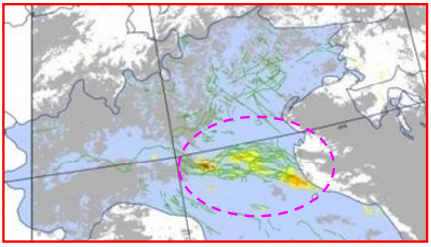

03 April 2009

01:25:37 GMT

$\square \otimes_{\Delta T}(\mathbf{r}, t) \geq 2$

$\otimes_{\Delta T}(\mathbf{r}, t) \geq 2,5$

$\otimes_{\Delta T}(\mathbf{r}, t) \geq 3$

clouds and no data

tectonic lineaments

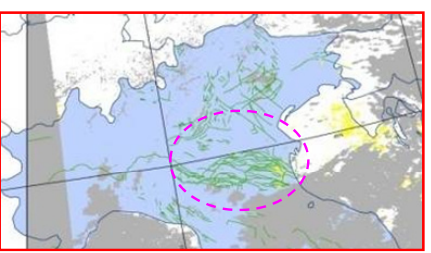

21 March 2009

00:20:58 GMT

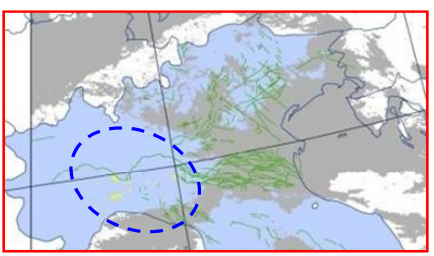

27 March 2009

00:58:36 GMT

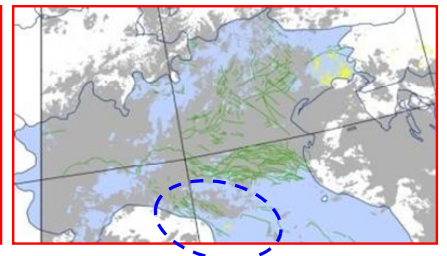

05 April 2009

01:04:33 GMT

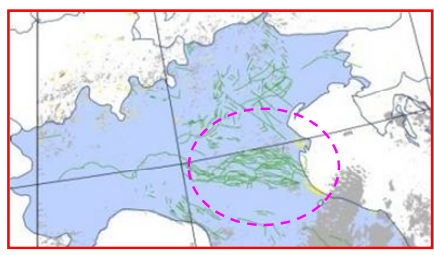

22 March 2009

01:46:30 GMT

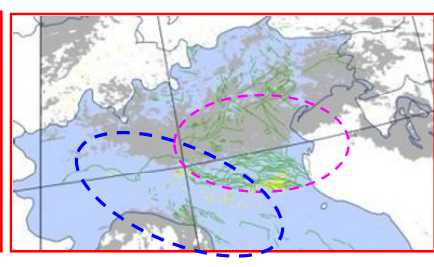

28 March 2009

00:43:50 GMT

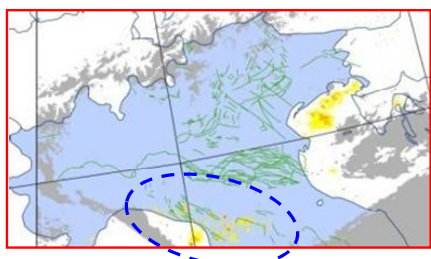

13 April̄ 20009

01:20:57 GMT

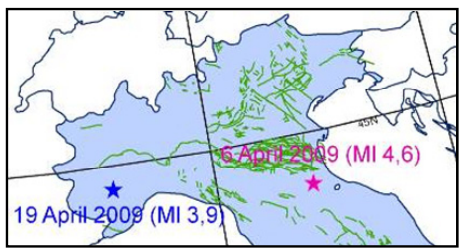

Bra and Forlì earthquakes epicenter

Fig. 6. Validation: as in Fig. 5 for the sequences of Forlì (5 April 2009, $M_{\mathrm{L}} \sim 4.6$ ) and Bra (19 April 2009, $M_{\mathrm{L}} \sim 3.9$ ) earthquakes described respectively by blue and purple dashed ellipses.

In Fig. 5 is represented the sequence of TIR anomalies affecting Central Italy. They appear located near tectonic lineaments, from 30 March (about $13 \mathrm{~h}$ before the strongest foreshock, with $M_{\mathrm{L}} \sim 4.1$, occurred on 30 March at 13:38 UTC) to 1 April when they reach their maximum extension (5 days before the mainshock of Abruzzo earthquake).

TIR anomalies with lower intensity and spatial extension can be observed from 8 to 10 April and again on 15 April.

In Fig. 6 are described two sequences of TIR anomalies observed in the Northern Italy. The first one is visible for several days between 16 March and 14 April in the north-west of Italy near the tectonic lineaments present in the Piedmont region and in the Apuane Alps (areas bordered by blue dashed ellipses) around the epicenter of Bra earthquake $\left(M_{\mathrm{L}} \sim 3.9\right)$ occurred in the same area on 19 April 2009 (INGV, 2009).
A second sequence of TIR anomalies is the one affecting Padania plain (areas bordered by purple dashed ellipses) with variable persistence in the space-time domain beginning from 16 March and continuing until 3 April (2 days before the Forli's earthquakes, $M_{\mathrm{L}} \sim 4.6$; INGV, 2009).

Figure 7 better describe TIR anomalies affecting Balkan region already present in Fig. 4.

From 16 March until 13 April the Balkan region is affected by a sequence of space-time persistent TIR anomalies preceding and following the occurrence of an earthquake occurred in the same area on 31 March $2009\left(M_{\mathrm{L}} \sim 4.2\right.$, INGV, 2009). 


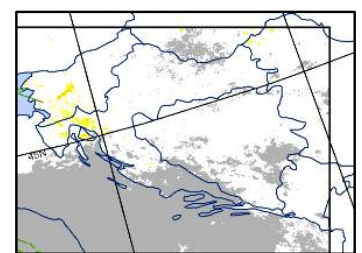

16 March 2009

01:13:44 GMT

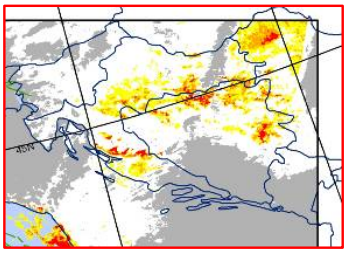

30 March 2009

00:22:57 GMT

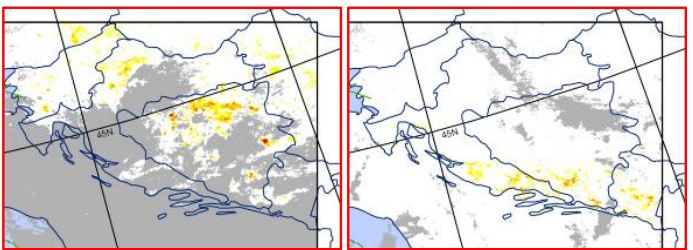

04 April 2009

01:15:03 GMT

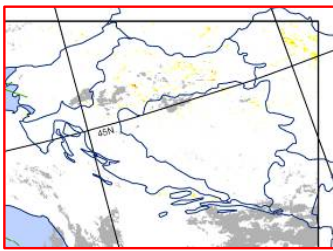

11 April 2009

00:53:13 GMT

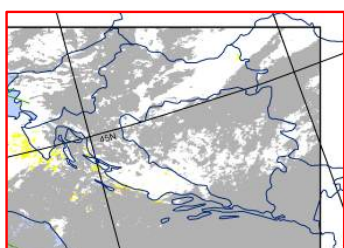

21 March 2009

00:20:58 GMT

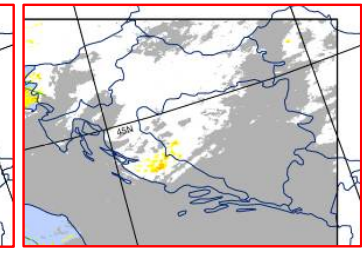

31 March 2009

01:57:31 GMT

06 April 2009

00:53:56 GMT

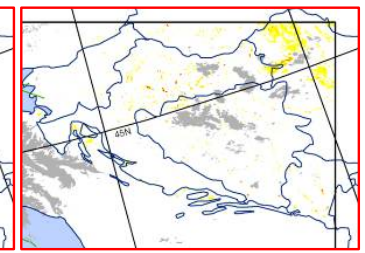

12 April 2009

01:31:13 GMT

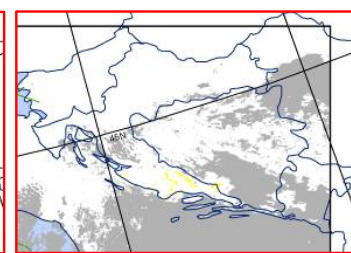

22 March 2009

01:46:30 GMT

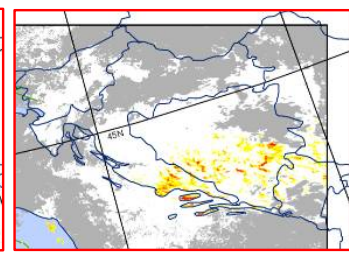

01 April 2009

01:46:49 GMT

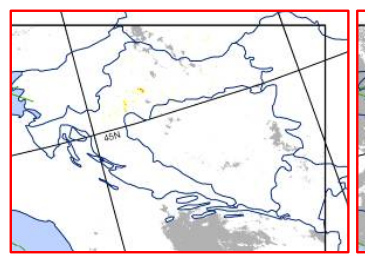

08 April 2009

00:32:49 GMT

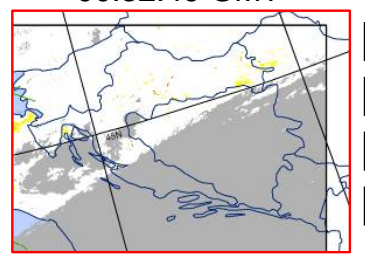

13 April 2009

01:20:57 GMT

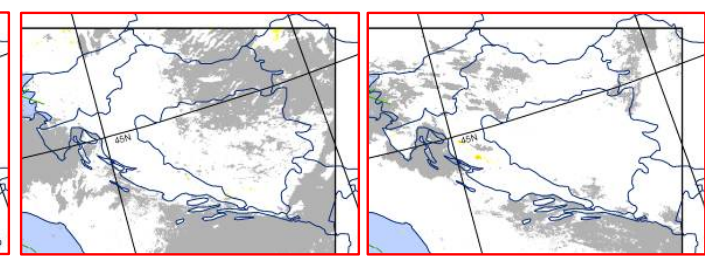

23 March 2009

01:35:59 GMT

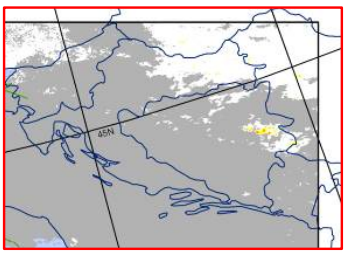

02 April 2009

01:36:14 GMT

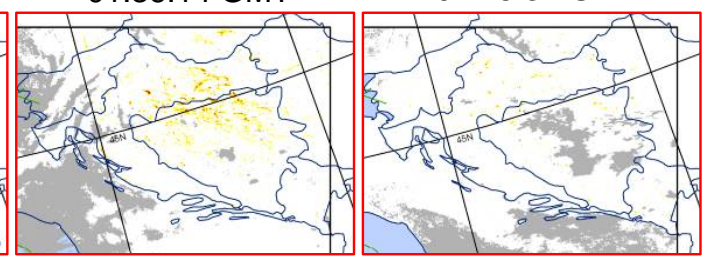

09 April 2009

01:13:47 GMT

10 April 2009

01:52:49 GMT

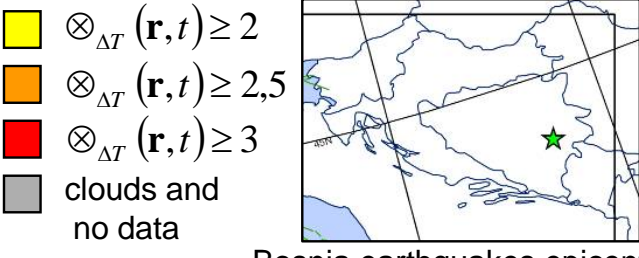

Bosnia earthquakes epicenter $31^{\text {st }}$ March $2009(\mathrm{Ml} 4,2)$

Fig. 7. Validation: as in Fig. 5 for the sequences of Balkan earthquake (31 March 2009, $M_{\mathrm{L}} \sim 4.2$ ).

\section{Confutation}

The confutation step has been performed by considering the same period (15 March-15 April) but in a different year (2008), in order to verify the absence of TIR anomalies in a relatively seismically unperturbed period. The selection of 2008 for confutation purposes has been done consulting the INGV (2009) seismic catalogue: no seismic event with magnitude greater than (or equal to) 4.5 is reported over the investigated area during the months of March and April 2008 (Fig. 8a). As for the validation step, the same cut at $3 \sigma$ (i.e. $\otimes_{\Delta T}(\boldsymbol{r}, t) \geq 3$ ) has been used in order to identify anomalous image pixels. As before scenes affected by a wide $(>80 \%)$ cloudy coverage are not shown (Fig. 8b).

Figure 9 shows the results of RST analysis performed for the 2008. It is possible to note that only isolated (on 16 March in north part of Italy and in Puglia region, 24 March in the north-east part of Balkan area, 27 March in Campania region, 2 April along Corsica coast, 9 April in Southern Apennines and 13 April on Bosnia region) and not time persistent (disappearing just in 1 day) TIR anomalies are detected. Other sporadic anomalies (1-2 pixels probably due to navigation errors) are present in some of the remaining analyzed days marked by red boxes in to indicate that they contain at least 1 pixel with RETIRA $>3$.

\section{Conclusions}

In this paper RST approach has been applied to the longest (15 years) time series of AVHRR images never used before for investigating possible space-time relation among TIR anomalies occurrence and earthquakes. Fifteen years of NOAA/AVHRR TIR observations have been used to characterize the expected TIR signal behavior in the absence of significant seismic activity. The period (15 March-15 April 2009) around the time of Abruzzo earthquake (6 April 2009, $M_{\mathrm{L}} \sim 5.8$ ) has been considered for validation purposes, while 


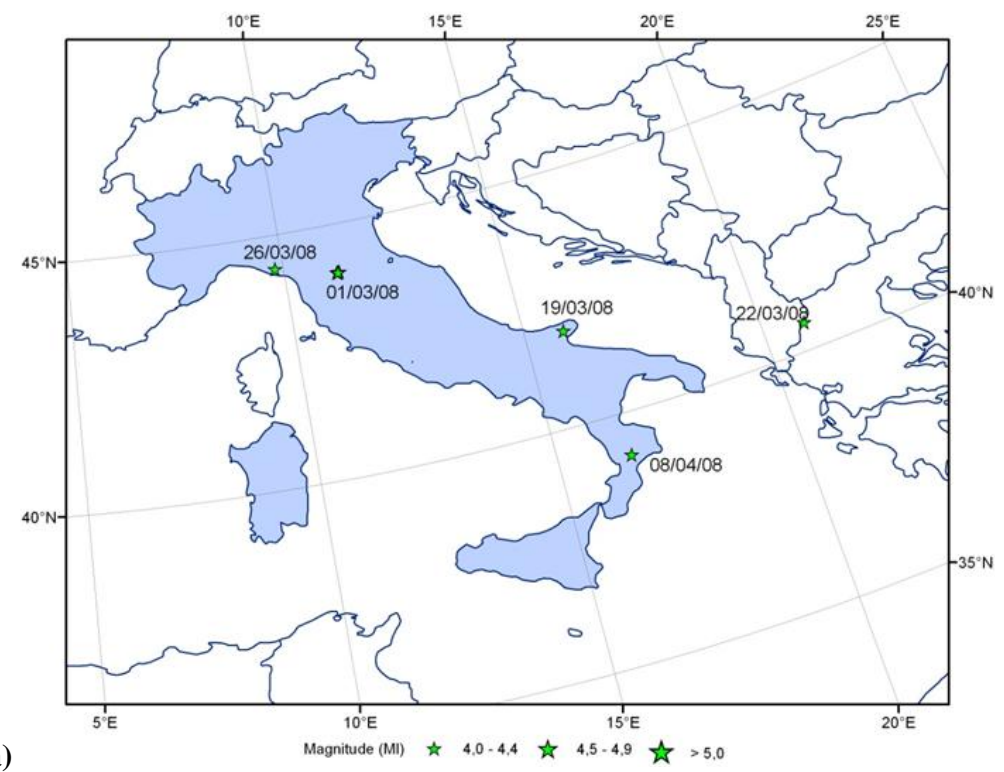

(a)
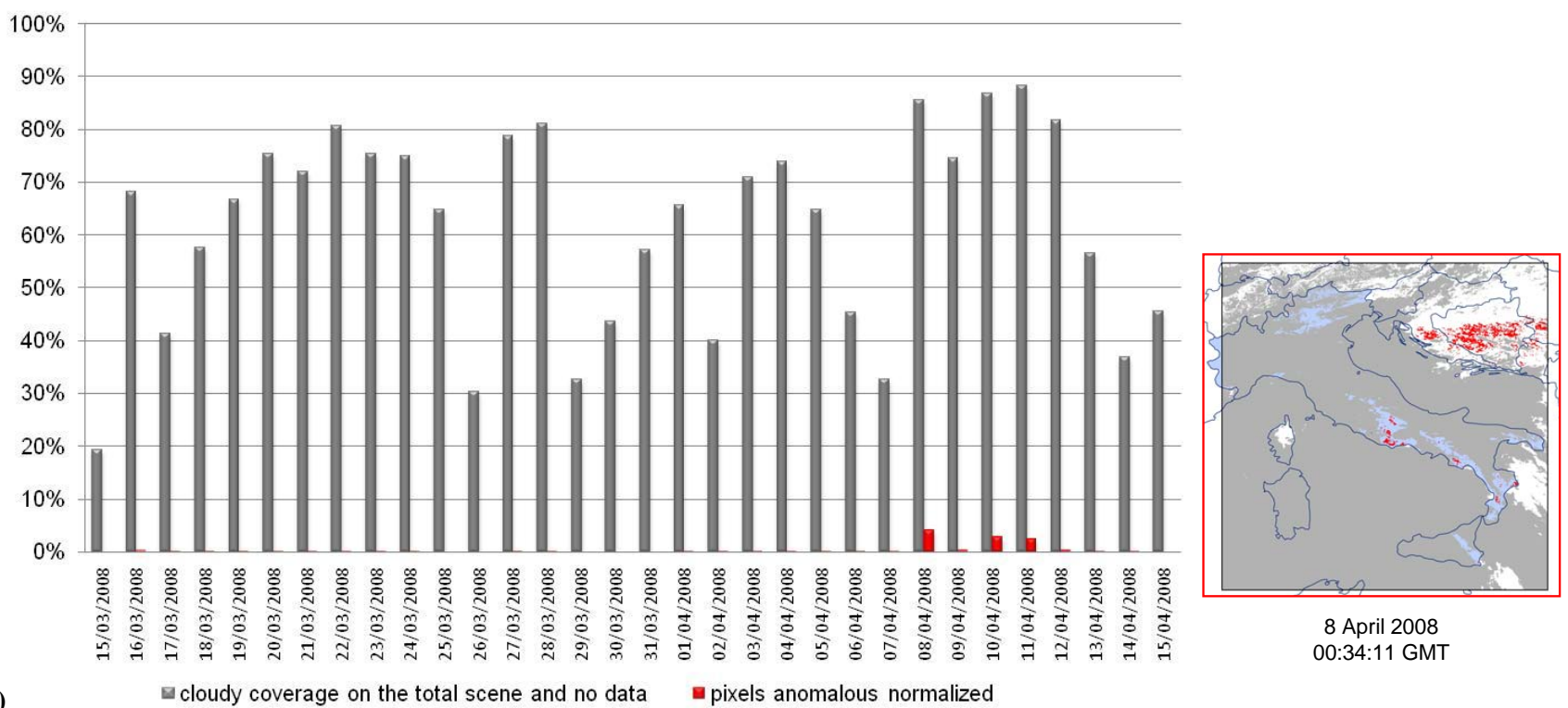

(b)

Fig. 8. (a) Seismic events $\left(M_{\mathrm{L}} \geq 4\right)$ occurred during March-April 2008 (INGV, 2009). (b) Left: calculation of cloudy coverage on all the scenes processed for 2008: grey bars represent the percentage of cloudy pixels over image; red bars represent the percentage of anomalous pixels over the remaining cloud free pixels in the image. Right: example on 8 April 2008 scene of artefacts (spurious TIR anomalies) due to the poorness of cloud-free pixels where RETIRA index can be computed and to the clouds masking most of the warmest part of the scene (cold spatial average effect, see text).

the same period in a relatively unperturbed year (2008, having no earthquakes with $M \geq 4.5$ ) was taken for confutation.

The comparison of results achieved after the validation/confutation analysis highlights the presence of several sequences of TIR anomalies with RETIRA index greater than 3 (never in the past a Signal-Noise ratio so high has been gotten using AVHRR data or other sensors onboard polar satellite, Filizzola et al., 2004; Aliano et al., 2008a).

In the validation phase, TIR anomalies have been identified in some space-time correlation with Abruzzo earthquake epicenter between 30 March and 1 April. In particular very intense and extended anomalies appear near tectonic lineaments since 30 March (few hours before the foreshock with $M_{\mathrm{L}} \sim 4.1$ ) during the same period interested by anomalous variations of different geophysical parameters independently reported by several authors (e.g., Caporali, 2009; Genzano et al., 2009; Pergola et al., 2010; Martinelli et al., 2009; Rozhnoi et al., 2009; Plastino et al., 2010). Among the others, particularly important seems the $V_{\mathrm{P}} / \mathrm{V}_{\mathrm{S}}$ seismological observations that Lucente et al. (2009) report with an explanatory 


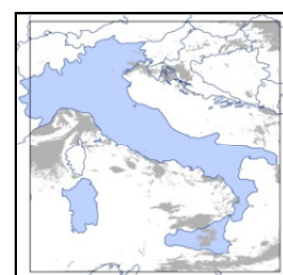

15 March 2008

01:23:21 GMT

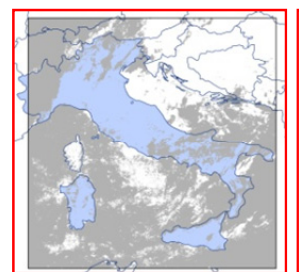

21 March 2008

00:20.35 GMT

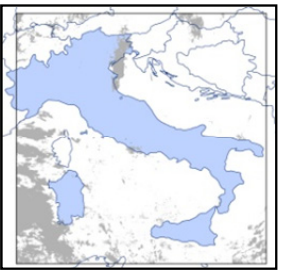

29 March 2008

00:37:55 GMT

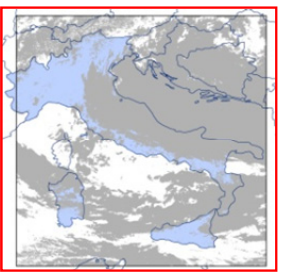

4 April 2008

01:47:37 GMT

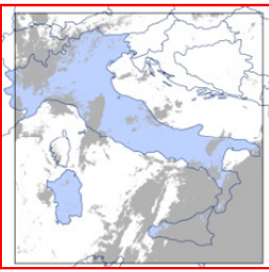

14 April 2008

01:12:19 GMT

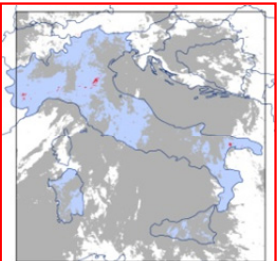

16 March 2008

01:12:52 GMT

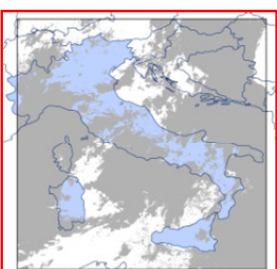

23 March 2008

01.40 .43 GMT

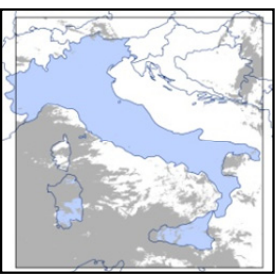

30 March 2008

00:27:22 GMT

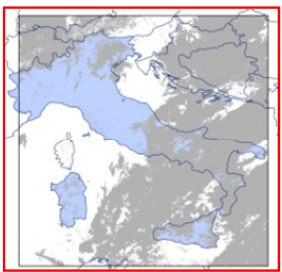

5 April 2008

01:05:38 GMT

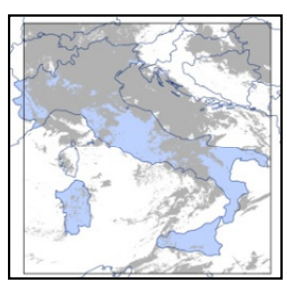

15 April 2008

01:01:55 GMT

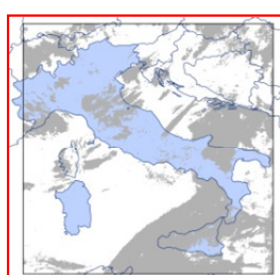

17 March 2008

01:02:29 GMT

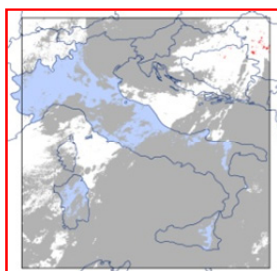

24 March 2008

01.30:14 GMT

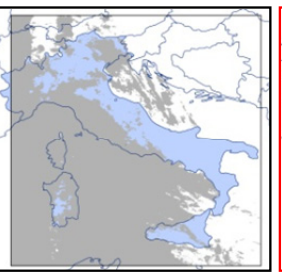

31 March 2008

00:16:59 GMT

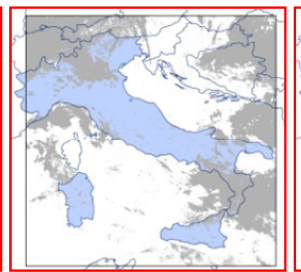

6 April 2008

00:55:10 GMT

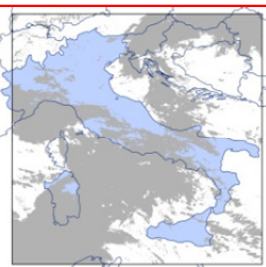

18 March 2008

00.52:00 GMT

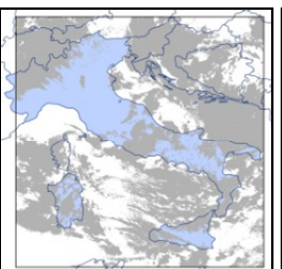

25 March 2008

01:19:43 GMT

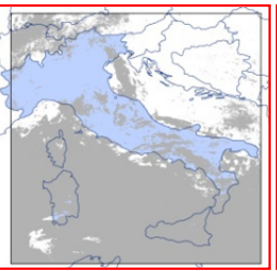

1 April 2008

01:47:37 GMT

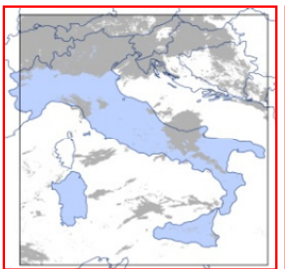

7 April 2008

00:44:40 GMT

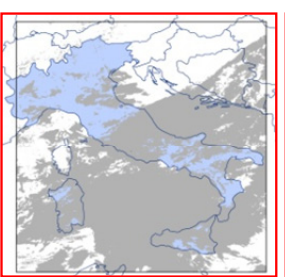

19 March 2008

00:41:34 GMT

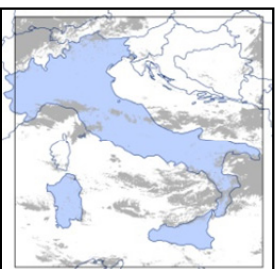

26 March 2008

01:09:15 GMT

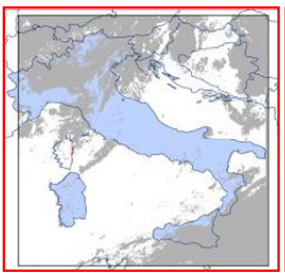

2 April 2008

01:37:03 GMT

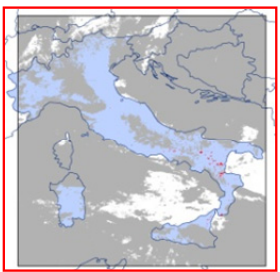

9 April 2008

00:19:52 GMT

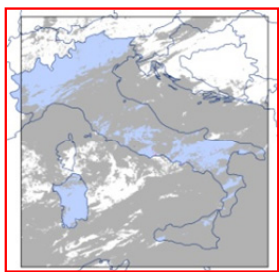

20 March 2008

00:31:00 GMT

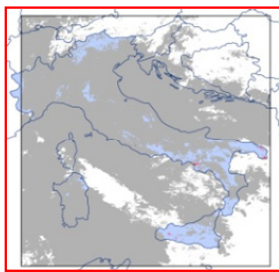

27 March 2008

00:58:49 GMT

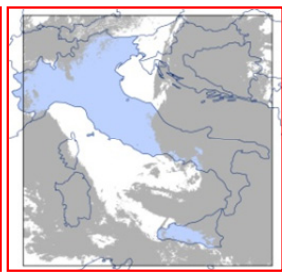

3 April 2008

01:47:37 GMT

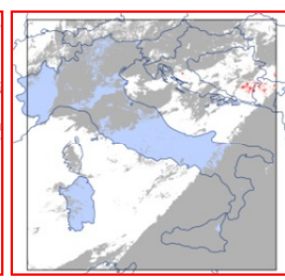

13 April 2008

01:22:48 GMT

Fig. 9. Confutation: as in Fig. 4 for the relatively unperturbed year 2008 (no earthquakes with $M_{\mathrm{L}}>5$ occurred in the same area and considered period). Red boxes contours the only images containing at least one pixel with $\otimes_{\Delta T}(\boldsymbol{r}, t) \geq 3$.

model which perfectly fits with the one proposed by Tramutoli et al. (2005) to explain TIR anomalies occurence in relation with abrupt increases of green-houses gases emissions.

The relation between TIR anomalies and the occurrence of earthquakes with medium-low magnitude, already found in previous work (e.g. Corrado et al., 2005) seems confirmed here, in fact TIR anomalies with some persistence in spacetime domain are visible near tectonic feature some days before seismic events of medium-low magnitude occurred at in Italy in the same period.

In the confutation phase, no similar significant TIR anomalies have been detected. 
Acknowledgements. The authors wish to thank "NEODAAS/University of Dundee" for its support in furnishing some of the AVHRR data used for the analysis of 2008 and 2009.

Edited by: P. F. Biagi

Reviewed by: A. Tronin and another anonymous referee

\section{References}

Aliano, C., Corrado, R., Filizzola, C., Pergola, N., and Tramutoli, V.: Robust Satellite Techniques (RST) For Seismically Active Areas Monitoring: The Case Of 21st May, 2003 Boumerdes/Thenia (Algeria) Earthquake, Proceedings of Multitemp 2007, 1-6, doi:10.1109/MULTITEMP.2007.4293042, 2007.

Aliano, C., Corrado, R., Filizzola, C., Genzano, N., Pergola, N., and Tramutoli, V.: TIR Satellite Techniques for monitoring Earthquake active regions: limits, main achievements and perspectives, Ann. Geofis., 51(1), 303-317, 2008a.

Aliano, C., Corrado, R., Filizzola, C., Pergola, N., and Tramutoli, V.: Robust satellite techniques (RST) for the thermal monitoring of earthquake prone areas: the case of Umbria-Marche October, 1997 seismic events, Ann. Geofis., 51, 2/3, 451-459, 2008b.

Aliano, C., Corrado, R., Filizzola, C., Genzano, N., Lanorte, V., Lisi, M., Martinelli, G., Pergola, N., and Tramutoli, V.: Robust Satellite Techniques for monitoring TIR anomalies in seismogenic areas, Proceedings of the Second Workshop on the Use of Remote Sensing Techniques for Monitoring Volcanoes and Seismogenic Areas, 2008c.

Bonfiglio, A., Macchiato, M., Pergola., N., Pietrapertosa, C., and Tramutoli, V.: AVHRR automated detection of volcanic clouds, Int. J. Remote Sens., 26(1), 9-27, 2005.

Caporali, A.: Time series of coordinates of CGPS stations in the area of the Abruzzo earthquakes, Oral discussion at "The April 2009 L'Aquila earthquake (Italy): first results and future strategies", Chieti, Italy, 4 June 2009.

Corrado, R., Caputo, R., Filizzola, C., Pergola, N., Pietrapertosa, C., and Tramutoli, V.: Seismically active area monitoring by robust TIR satellite techniques: a sensitivity analysis on low magnitude earthquakes in Greece and Turkey, Nat. Hazards Earth Syst. Sci., 5, 101-108, 2005,

http://www.nat-hazards-earth-syst-sci.net/5/101/2005/.

Cuomo, V., Lasaponara, R., and Tramutoli, V.: Evaluation of a new satellite-based method for forest fire detection, Int. J. Remote Sens., 22(9), 1799-1826, 2001.

Cuomo, V., Filizzola, C., Pergola, N., Pietrapertosa, C., and Tramutoli, V.: A self-sufficient approach for GERB cloudy radiance detection, Atmos. Res., 72(1-4), 39-56, 2004.

Di Bello, G., Filizzola, C., Lacava, T., Marchese, F., Pergola, N., Pietrapertosa, C., Piscitelli, S., Scaffidi, I., and Tramutoli, V.: Robust Satellite Techniques for Volcanic and Seismic Hazards Monitoring, Ann. Geophys., 47(1), 49-64, 2004.

Filizzola, C., Pergola, N., Pietrapertosa, C., and Tramutoli, V.: Robust satellite techniques for seismically active areas monitoring: a sensitivity analysis on September 7, 1999 Athens's earthquake, Phys. Chem. Earth, 29, 517-527, 2004.

Filizzola, C., Lacava, T., Marchese, F., Pergola, N., Scaffidi, I., and Tramutoli, V.: Assessing RAT (Robust AVHRR Techniques) performances for volcanic ash cloud detection and monitoring in near realtime: The 2002 eruption of Mt. Etna (Italy), Remote Sens. Environ., 107, 440-454, 2007.

Genzano, N., Aliano, C., Filizzola, C., Pergola, N., and Tramutoli, V.: A robust satellite technique for monitoring seismically active areas: The case of Bhuj-Gujarat earthquake, Tectonophysics, 431, 197-210, 2007.

Genzano, N., Aliano, C., Corrado, R., Filizzola, C., Lisi, M., Paciello, R., Pergola, N., Tsamalashvili, T., and Tramutoli, V.: Assessing of the Robust Satellite Techniques (RST) in areas with moderate seismicity, in: Multitemp 2009, Fifth International Workshop on the Analysis of Multitemporal Remote Sensing Images, Mistic, Connecticut, USA, 307-314, 28-30 July 2009.

Genzano, N., Aliano, C., Corrado, R., Filizzola, C., Lisi, M., Mazzeo, G., Paciello, R., Pergola, N., and Tramutoli, V.: RST analysis of MSG-SEVIRI TIR radiances at the time of the Abruzzo 6 April 2009 earthquake, Nat. Hazards Earth Syst. Sci., 9, 2073-2084, 2009, http://www.nat-hazards-earth-syst-sci.net/9/2073/2009/.

Gorny, V. I., Salman, A. G., Tronin, A. A., and Shilin, B. B.: The Earth outgoing IR radiation as an indicator of seismic activity, P. Acad. Sci. USSR, 301, 67-69, 1988.

Hamza, V. M.: Tectonic leakage of fault bounded aquifers subject to non-isothermal recharge: A mechanism generating thermal precursors to seismic events. Phys. Earth Planet. In., 126, 163-177, 2001.

INGV (Istituto Nazionale di Geofisica e Vulcanologia): The Italian seismic bullettin, available at: http://iside.rm.ingv.it/iside/ standard/index.jsp, 2009.

Lacava, T., Cuomo, V., Di Leo, E. V., Pergola, N., Romano, F., and Tramutoli, V.: Improving soil wetness variations monitoring from passive microwave satellite data: the case of April 2000 Hungary flood, Remote Sens. Environ., 96/2, 135-148, 2005.

Lacava, T., Di Leo, E. V., Pergola, N., and Tramutoli, V.: Spacetime soil wetness variations monitoring by a multi-temporal microwave satellite records analysis, Phys. Chem. Earth, 31, 12741283, 2006.

Lacava, T., Filizzola, C., Pergola, N., Sannazzaro, F. and Tramutoli, V. Improving flood monitoring by RAT (Robust AVHRR Technique) approach: the case of April 2000 Hungary flood, Int. J. Remote Sens., in press, 2010.

Lucente, F. P., De Gori, P., Margheriti, L., Piccinini, D., DiBona, M., Chiarabba, C., and Piana Agostinetti, N.: The preparatory phase of the April 6th 2009, Mw 6.3, L'Aquila earthquake: Seismological observations, Oral discussion at AGU Fall Meeting 2009, San Francisco, California, USA, 14-18 December 2009.

Marchese, F., Pergola, N., and Telesca, L.: Investigating the temporal fluctuations in satellite Advanced very High Resolution Radiometer thermal signals measured in the volcanic area of Etna (Italy), Fluctuations Noise Lett., 6(3), 305-316, 2006.

Martinelli, G., Heinicke, J., and Italiano, F.: Variazioni nel flusso di $\mathrm{CO}_{2}$ osservate nel marzo-aprile 2009 in Italia centrale, Atti del GNGTS 2009, Trieste, Italy, available at: http://www2.ogs.trieste.it/gngts/gngts/index.php?option= com_content $\backslash \&$ task=view\&id=71 \\&Itemid=163, $\quad 16-19$ November 2009 (in Italian).

Mazzeo, G., Marchese, F., Filizzola, C., Pergola, N., and Tramutoli, V. A.: Multi-temporal Robust Satellite Technique (RST) for forest fire detection, in: Multitemp 2007, Louven, Belgium, 1-6, doi:10.1109/MULTITEMP.2007.4293060, 18-20 July 2007. 
Ouzounov, D. and Freund, D.: Mid-infrared emission prior to strong earthquakes analyzed by remote sensing data, Adv. Space Res., 33, 268-273, 2004.

Pergola, N., Pietrapertosa, C., Lacava, T., and Tramutoli, V.: Robust satellite techniques for monitoring volcanic eruptions, Ann. Geophys., 44(2), 167-177, 2001.

Pergola, N. and Tramutoli, V.: SANA: Sub-pixel Automatic Navigation of AVHRR imagery, Int. J. Remote Sens., 21(12), 25192524, 2000

Pergola, N. and Tramutoli, V.: Two years of operational use of SANA (sub-pixel automatic navigation of AVHRR) scheme: accuracy assessment and validation, Remote Sens. Environ., 82(2), 190-203, 2003

Pergola, N., Tramutoli, V., and Marchese, F.: Automated detection of thermal features of active volcanoes by means of infrared AVHRR records, Remote Sensing Environ., 93, 311-327, 2004a.

Pergola, N., Tramutoli, V., Scaffidi, I., Lacava, T., and Marchese, F.: Improving volcanic ash clouds detection by a robust satellite technique, Remote Sens. Environ., 90(1), 1-22, 2004b.

Pergola, N., Aliano, C., Coviello, I., Filizzola, C., Genzano, N., Lacava, T., Lisi, M., Mazzeo, G., and Tramutoli, V.: Using RST approach and EOS-MODIS radiances for monitoring seismically active regions: a study on the 6 April 2009 Abruzzo earthquake, Nat. Hazards Earth Syst. Sci., 10, 239-249, 2010, http://www.nat-hazards-earth-syst-sci.net/10/239/2010/.

Pietrapertosa, C., Pergola, N., Lanorte, V., and Tramutoli, V.: Self Adaptive Algorithms for Change Detection: OCA (the Onechannel Cloud-detection Approach) an adjustable method for cloudy and clear radiances detection, in: Technical Proceedings of the Eleventh International (A) TOVS Study Conference (ITSC-XI), Budapest, 20-26 September 2000, edited by: Le Marshall, J. F. and Jasper, J. D., Bureau of Meteorology Research Centre, Melbourne, 281-291, 2001.

Plastino, W., Povinec, P. P., De Luca, G., Doglioni, C., Nisi, S., Ioannucci, L., Ballata, M., Laubenstein, M., Bella, F., and Coccia, E.: Uranium groundwater anomalies and l'Aquila earthquake, 6th April 2009 (Italy), J. Environ. Radioactiv., doi:10.1016/j.jenvrad.2009.08.009, in press, 2010.

Pulinets, S. A., Boyarchuk, K. A., Hegai, V. V., and Karelin, A. V.: Conception and model of seismo-ionospheremagnetosphere coupling, in: Seismo-Electromagnetics: Lithosphere-Atmosphere-Ionosphere Coupling, edited by: Hayakawa, M. and Molchanov, O. A, Terra Scientific Publishing Co., Tokyo, 353-361, 2002.

Pulinets, S. A., Ouzounov, D., Karelin, A. V., Boyarchuk, K. A., and Pokhmelnykh, L.A.: The physical nature of thermal anomalies observed before strong earthquakes, Phys. Chem. Earth, 31, 143153, 2006.

Pulinets, S. A., Biagi, P., Tramutoli, V., Legen'ka, A. D., and Depuev, V. K.: Irpinia earthquake 23 November 1980 - Lesson from Nature reviled by joint data analysis, Ann. Geophys., 50(1), 61-78, 2007.

Qiang, Z. J. and Dian, C. G.: Satellite thermal infrared impending temperature increase precursor of Gonghe earthquake of magnitude 7.0, Qinghai Province, Geoscience, 6(3), 297-300, 1992.

Qiang, Z. J., Xu, X. D., and Dian, C. G.: Thermal infrared anomaly precursor of impending earthquakes, Chinese Sci. Bull., 36(4), 319-323, 1991.
Qiang, Z. J., Xu, X. D., and Dian, C. G.: Thermal infrared anomaly precursor of impending earthquakes, Pure Appl. Geophys., 149, 159-171, 1997.

Rozhnoi, A., Solovieva, M., Molchanov, O., Schwingenschuh, K., Boudjada, M., Biagi, P. F., Maggipinto, T., Castellana, L., Ermini, A., and Hayakawa, M.: Anomalies in VLF radio signals prior the Abruzzo earthquake $(M=6.3)$ on 6 April 2009, Nat. Hazards Earth Syst. Sci., 9, 1727-1732, 2009, http://www.nat-hazards-earth-syst-sci.net/9/1727/2009/.

Tramutoli, V.: Robust AVHRR techniques (RAT) for environmental monitoring: theory and applications, Earth surface remote sensing II, in: Proceedings of SPIE, 3496, 101-113, 1998.

Tramutoli, V.: Robust Satellite Techniques (RST) for natural and environmental hazards monitoring and mitigation: ten years of successful applications, in: ISP MSRS 2005 Conference Proceedings, Beijing, China, 2005.

Tramutoli, V.: Robust Satellite Techniques (RST) for Natural and Environmental Hazards Monitoring and Mitigation: Theory and Applications, Proceedings of Multitemp 2007, 1-5, doi:10.1109/MULTITEMP.2007.4293057, 2007.

Tramutoli, V., Aliano, C., Corrado, R., Filizzola, C., Genzano, N., Lisi, M., Lanorte, V., Tsamalashvili, T., and Pergola, N.: Abrupt change in greenhouse gases emission rate as a possible genetic model of TIR anomalies observed from satellite in Earthquake active regions, in: Proceedings of 33rd International Symposium on Remote Sensing of Environment (ISRSE33), Stresa, Lago Maggiore, Italy, 4-8 May 2009.

Tramutoli, V., Claps, P., Marella, M., Pergola, N., Pietrapertosa, C., and Sileo, C.: Hydrological implications of remotelysensed thermal inertia, in: Remote Sensing and Hydrology 2000, vol. 267, edited by: Owe, M., Brubaker, K., Ritchie, J., and Rango, A., IAHS Publ., 207-211, 2001a.

Tramutoli, V., Di Bello, G., Pergola, N., and Piscitelli, S.: Robust satellite techniques for remote sensing of seismically active areas, Ann. Geophys., 44(2), 295-312, 2001b.

Tramutoli, V., Pergola, N., and Pietrapertosa, C.: Training on NOAAAVHRR of robust satellite techniques for next generation of weather satellites: an application to the study of spacetime evolution of Pinatubo's stratospheric volcanic cloud over Europe, in: IRS 2000: Current Problems in Atmospheric Radiation, edited by: Smith, W. L. and Timofeyev, Yu. M., VA' Deepak Publishing, Hampton, 36-39, 2001c.

Tramutoli, V., Cuomo, V., Filizzola, C., Pergola, N., and Pietrapertosa, C.: Assessing the potential of thermal infrared satellite surveys for monitoring seismically active areas: The case of Kocaeli (Izmit) earthquake, August 17, 1999, Remote Sens. Environ., 96 , 409-426, 2005.

Tronin, A. A.: Satellite thermal survey - a new tool for the study of seismoactive regions, Int. J. Remote Sens., 41(8), 1439-1455, 1996.

Tronin, A. A.: Thermal IR satellite sensor data application for earthquake research in China, Int. J. Remote Sens., 21(16), 31693177, 2000.

Tronin, A. A., Hayakawa, M., and Molchanov, O. A.: Thermal IR satellite data application for earthquake research in Japan and China, J. Geodyn., 33(4-5), 519-534, 2002. 